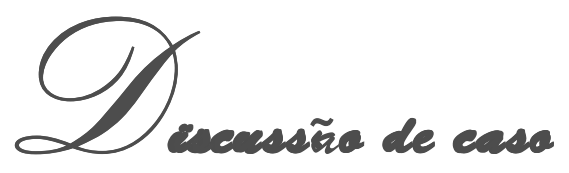

\title{
ANGIOENDOTELIOMA ENDOVASCULAR COM METÁSTASES EM CLITÓRIS E MAMA
}

Caso Clínico: T.G.M., 67 anos, branca, casada, natural de São Paulo, deu entrada no Serviço de Oncologia Ginecológica do CRSM com queixa de nódulo e dor em região vulvar há seis meses; referia menarca aos 13 anos, menopausa aos 50 anos e três partos normais. Em relação aos antecedentes clínicos não havia nada digno de nota e, cirúrgico, referia a realização de biópsia de nódulo localizado no terço médio da coxa esquerda, há três anos, cujo anatomopatológico evidenciou angioendotelioma maligno, não tendo recebido qualquer tratamento após o diagnóstico. Os exames físico e ginecológico constataram a presença de um tumor de $3 \mathrm{~cm}$ no clitóris (Fig. 2), múltiplos nódulos mamários bilateralmente (Fig. 3), linfadenomegalia inguinal esquerda e três lesões tumorais ulceradas de aproximadamente $4 \mathrm{~cm}$ de diâmetro cada uma, em membro inferior esquerdo (Fig. I). Os exames complementares incluíram radiografia de tórax, que constatou múltiplas lesões parenquimatosas pulmonares compatíveis com tumores metastáticos (Fig. 4), e mamografia, com múltiplos nódulos bilaterais (Fig. 5). As biópsias do tumor de clitóris e mama revelaram 0 angioendotelioma vascular maligno. A paciente foi a óbito antes da tentativa de tratamento quimioterápico, que tinha sido indicada por se tratar de doença sistêmica.

\section{Comentário}

0 angioendotelioma endovascular maligno é um tumor vascular raro, caracterizado por proliferação papilar das células endoteliais dentro do lúmen vascular e que pode envolver pele ou tecido celular subcutâneo. É de crescimento infiltrativo, com risco de metástases para os linfonodos regionais, e apresenta alta taxa de recorrência local após tratamento cirúrgico. 0 angionedotelioma endovascular maligno, também denominado tumor de Dabska, é um angiosarcoma de baixo grau de malignidade e foi descrito pela primeira vez em 1969. A literatura, até então, revelava se tratar de tumor com incidência rara, acometendo exclusivamente crianças e adolescentes e somente uma morte tinha sido descrita por esse tipo de tumor. 0 tratamento cirúrgico, exérese da lesão, é a conduta de escolha, pois apresenta elevada porcentagem de cura; apesar de incomuns, podem ocorrer tanto a recorrência local como o aparecimento de novos tumores.

Este relato de caso, ao fornecer importantes informações, certamente contribuirá para o melhor entendimento da evolução natural da doença (quando não tratada) e de seu comportamento metastático, mesmo sendo

Fig. I - Lesóes em coxa esquerda de três anos de evolução, sem qualquer tratamento

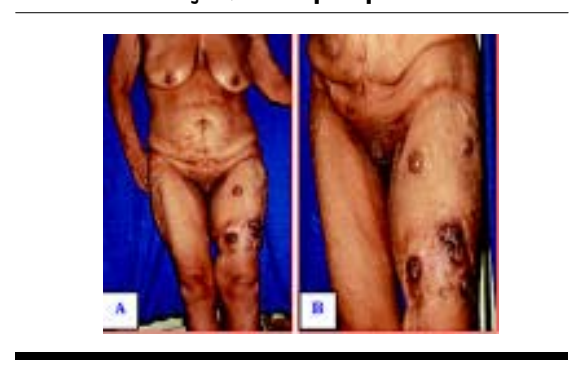

Fig. 2 - Lesão de $3 \mathrm{~cm}$ de diâmetro no clitóris
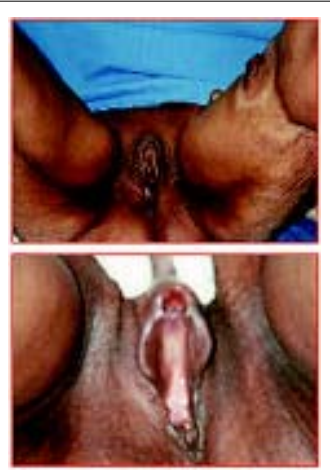

Fig. 3 - Presença de múltiplas lesões nodulares subcutâneas $e$ intraparenquimatosas nas mamas

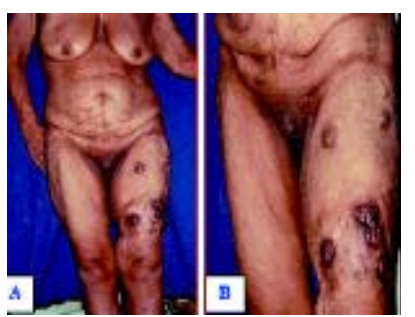

um sarcoma de baixo grau de malignidade.

Deve ser ressaltado que até hoje não existe, na literatura científica veiculada pela internet, qualquer referência deste tumor em pacientes nesta faixa etária e com comprometimento mamário e de genitais, daí considerarmos de interesse para o ginecologista.

Fig. 4 - Presença de múltiplas lesões infiltrativas pulmonares intraparenquimatosas

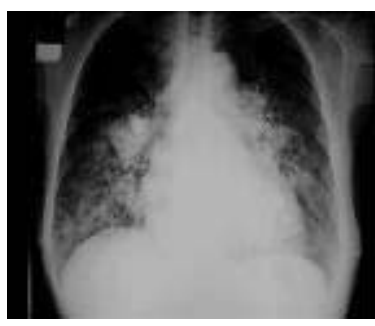

Fig. 5 - Mamografia com formações nodulares bilaterais $(A$ e $B)$

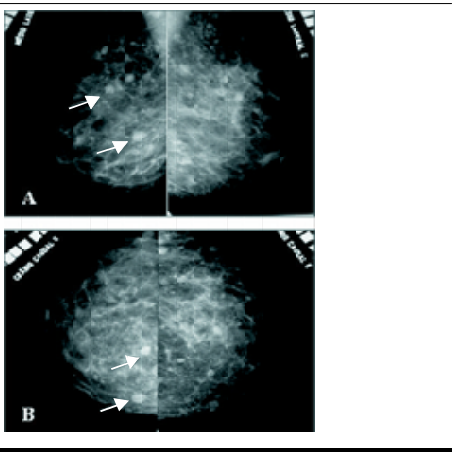

Israel Nunes Alecrin, Daniella Moreira, Luiz Fernando Ramirez, Fábio Martins laginha, José Antônio Marques, José Mendes Aldrighi

Centro de Referência da Saúde da Mulher (CRSM) - São Paulo - SP 